\title{
Description of mechanical properties of carbon nanotubes. Tube wall thickness problem. Size effect. Part 1
}

\author{
R.V. Goldstein ${ }^{1}$, V.A. Gorodtsov ${ }^{1, \dagger}$, A.V. Chentsov ${ }^{1}$, S.V. Starikov', \\ V.V. Stegailov' ${ }^{2}$ G.E. Norman ${ }^{2}$ \\ †gorod@ipmnet.ru
}

\begin{abstract}
${ }^{1}$ A.Yu. Ishlinsky Institute for Problems in Mechanics RAS, prospect Vernadskogo 101-1, 119526 Moscow
\end{abstract}
${ }^{2}$ Joint Institute of High Temperatures RAS, Izhorskaya 13, 125412 Moscow

\section{К описанию механических свойств углеродных нанотрубок. Проблема толщины трубки. Масштабный эффект. Часть 1}

\author{
Гольдштейн Р.В. ${ }^{1}$, Городцов В.А. ${ }^{1}$, Ченцов А.В. ${ }^{1}$, Стариков С.В. ${ }^{2}$, \\ Стегайлов В.В. ${ }^{2}$, Норман Г.Е. ${ }^{2}$ \\ ${ }^{1}$ Институт проблем механики им. А.Ю. Ишлинского РАН, просп. Вернадского 101-1, 119526 Москва \\ ${ }^{2}$ Объединенный институт высоких температур РАН, ул. Ижорская 13, 125412 Москва
}

In many publications the classical theory of elasticity is used to describe the mechanical properties of nanotubes. However, necessary conditions for applicability of the theory of elasticity are not fulfilled in the case of singlewalled carbon nanotubes (SWCNTs) and tubes with a small number of atomic layers in their walls. Therefore, in the first part of this article, we introduce the method of molecular dynamics and general energy analysis for the description of the generalized Young's modulus (with the dimension of the surface stiffness) and Poisson's ratio characterizing the uniaxial tension of SWCNTs. The strong dependence of the generalized characteristics of the studied nanoscales is their distinctive feature (size effect) which is in contrast to the similar concepts of the elasticity theory.

Here in Part 1 we discussed features of the basic approach and the semi-empirical Tersoff-Brenner-Stewart potential used in the present study. The main findings will be presented in Part 2.

Keywords: carbon nanotubes, mechanical properties, elasticity, size effect, Yakobson`s paraox, molecular dynamic, Tersoff-BrennerStuart potential.

\section{Introduction}

Nanotubes, including carbon and non-carbon nanotubes, have already been intensively studied for almost two decades (the starting articles $[1,2]$ ). It is common that the description
При описании механических свойств нанотрубок во многих публикациях используется классическая теория упругости. Однако в случае однослойных углеродных нанотрубок и трубок с малым числом атомных слоев в их стенках не выполняются условия, необходимые для применимости приближения теории упругости. Поэтому в первой части данной статьи мы используем метод молекулярной динамики и общего энергетического анализа для описания обобщенного модуля Юнга (с размерностью поверхностной жесткости) и коэффициента Пуассона, характеризующих одноосное растяжение однослойных углеродных нанотрубок. Сильная зависимость таких обобщенных характеристик от исследуемых наномасштабов оказывается их отличительной особенностью (масштабный эффект) в отличие от аналогичных понятий теории упругости.

Здесь, в части 1 мы подробно обсуждаем особенности принятого подхода и используемого полуэмпирического потенциала Терсоффа-Бреннера-Стюарта. Основные полученные результаты будут изложены в части 2.

Ключевые слова: углеродные нанотрубки, механические свойства, упругость, масштабный эффект, парадокс Якобсона, молекулярная динамика, потенциал Терсоффа-Бреннера-Стюарта.

of nanotubes mechanical properties is based on macroscopic ideas. Basic concepts (like Young's modulus, Poisson's ratio etc.) are borrowed from the classic elasticity theory without sufficient basis. The molecular modeling methods bring 
the understanding of the role of discrete atomic structures. However, in this case the concepts of the elasticity theory are also needed for the results interpretation.

By now a lot of literary data on experimental studies of SWCNTs elastic properties (along with various methods of measurement) are available [3-43]. In the field of theoretical predictions of SWCNTs elastic properties there is even more progress [44-51]. The results of these studies are essentially varied from one researcher to another (by more than an order of magnitude for Young's modulus). This scatter is known as "Yakobson's paradox" [52]. Along with inaccuracies of the experimental measurements, the experimental and theoretical researches clash with difficulties of the interpretations of results. The concepts of continuum mechanics and classic elasticity theory are usually used even for interpretation of molecular-dynamics simulations. However, the necessary conditions of continuum mechanics applicability are often violated. Namely the violation of the superiority of object size L over the atomic and interatomic scale a (i.e. $L>>$ a) is observed. In present work for the further estimates this strong inequality will be replaced with the specific inequality $\mathrm{L}>>10$ a providing accuracy in one order of magnitude.

Nanotubes are such long objects so that this inequality is fulfilled practically always. Moreover, the length of nanotubes can reach millimeters, i.e. length can be of a macroscopic value. The condition on nanotubes circumferential dimension is also not essentially restrictive. For carbon nanotubes the interatomic distance in graphene plane is the length of a covalent $\mathrm{C}-\mathrm{C}$ bond $0.142 \mathrm{~nm}$. Then the continuum approximation is possible for nanotubes with inner diameter more than $10 \mathrm{a} / \pi \approx 0.45 \mathrm{~nm}$. The smallest known diameter of a synthesized SWCNT is $0.33 \mathrm{~nm}$ [53] and the smallest internal diameter of MWCNT is $0.3 \mathrm{~nm}$ [54]. Therefore large number of nanotubes satisfies the discussed condition for the circumferential perimeter of nanotubes. However, there is another cross-section direction of nanotubes, namely their thickness direction. The scale restriction $h \geq 10 \mathrm{a}$ can be carried out only for thick MWCNT. This inequality states the number of layers not less than ten. In this case the distance between graphene layers equals $\mathrm{a}=0.34 \mathrm{~nm}$. Therefore the critical thickness of a wall is about $\mathrm{h} \approx 3.5 \mathrm{~nm}$, and then for the minimal external diameter of nanotubes we have an estimate $\mathrm{D}_{0} \approx 7.5 \mathrm{~nm}$. For MWCNT of smaller diameters the influence of discrete atomic structure on mechanical properties (scale effect) can be expected. In case of SWCNTs the concept of thickness is generally ill-determined. Note, that it occurs periodic alternation of atoms and "empty" places in the graphene layer from which the nanotube is formed. Hence, the clear physical sense of fixing any thickness of this layer is absent.

The problem of carbon nanotube thickness and Young's modulus determination (both problems are closely connected) were repeatedly discussed in the scientific literature [55-61]. On the basis of these discussions one can conclude that introduction of the concept of thickness is not necessary for thin-walled nanotubes mechanical properties description. There are deformation characteristics of nanotubes which are still well-determinable at discrete atomic simulation as well as at continuum approximation, i.e. the energy of deformation and its derivatives on strain $\partial \mathrm{W} / \partial \varepsilon, \partial^{2} \mathrm{~W} / \partial \varepsilon^{2}, \ldots$. The first derivative of $\mathrm{W}$ at nanotube axial tension - compression defines the force $\left(l_{0}\right.$ - initial nanotube length)

$$
\mathrm{F}=\frac{\partial \mathrm{W}}{\partial \mathrm{l}}=\frac{1}{1_{0}} \frac{\partial \mathrm{W}}{\partial \varepsilon}, \varepsilon=\frac{1-1_{0}}{1_{0}} .
$$

For infinitesimal strain $(\varepsilon \rightarrow 0)$ the second derivative of W gives an important mechanical characteristic which can be called «generalized Young's modulus» or a surface stiffness (with dimensionality $\mathrm{Pa} \cdot \mathrm{m}=10^{-3} \mathrm{TPa} \cdot \mathrm{nm}$ )

$$
\left.\mathrm{E}_{\mathrm{s} 0} \equiv \frac{1}{\mathrm{~S}} \frac{\partial^{2} \mathrm{~W}}{\partial \varepsilon^{2}}\right|_{\varepsilon=0}=\left.\frac{1}{2 \pi \mathrm{r}} \frac{\partial \mathrm{F}}{\partial \varepsilon}\right|_{\varepsilon=0} .
$$

Here $\mathrm{S}$ - the area of a nanotube surface, $\mathrm{r}$ - its radius. This characteristic was used in several studies [55-61]. It is suitable for the description of MWCNTs as well as for SWCNTs. However, only for the MWCNTs with sufficiently large diameter $\left(D_{0} \geq 10 \mathrm{~nm}\right)$ the necessary scale inequalities are realized for all directions. MWCNT is like a single crystal graphite locally. Then the conditions of classical elasticity theory concepts applicability are fulfilled and the sense of nanotube thickness is clear. In this case the surface stiffness becomes the traditional in-plane stiffness proportional to Young's modulus multiplied by thickness of a nanotube $\mathrm{E}_{\mathrm{s} 0} \approx \mathrm{Eh}$. The thickness of a nanotube $\mathrm{h}$ is equal to $\mathrm{N} \cdot \mathrm{a} \approx \mathrm{N} \cdot 0.35 \mathrm{~nm}$, where $\mathrm{N}$ is number of layers and $\mathrm{a}$ is the distance between the graphene plates for graphite. At the same time the determination of Young's modulus is incorrect for SWCNTs because of the indefiniteness of thickness $h$. At first sight it seems possible to calculate independently the thickness $h$ and Young's modulus computing other elastic characteristics (e.g., bending or torsion stiffness). However, this formal method gives the non-physical results for SWCNTs [60].

For SWCNTs one can calculate Poisson's ratio. This is possible because the length and circumferential perimeter of a nanotube are "macroscopic" well-determined quantities. Such generalized ratio can be calculated by the ratio of a relative change of nanotube circumferential size to the relative change of nanotube length

$$
v=-\frac{\Delta s / s_{0}}{\Delta 1 / 1_{0}}=-\frac{\Delta r / r_{0}}{\Delta 1 / 1_{0}}=\frac{r-r_{0}}{\varepsilon r_{0}}
$$

Thereby Poisson's ratio can be used for nanotube mechanical properties description together with generalized Young's modulus. However, if the inequality $r_{0}>>\Delta r>>a$ is not satisfied then the scale effect for Poisson's ratio is possible. In the classic elasticity theory Poisson's ratio is a constant.

In the elasticity theory any elastic characteristic of isotropic medium is defined through only two independent values, for instance by Young's modulus and Poisson's ratio. For nanotubes with large diameter two similar generalized characteristics reduce to these elastic constants as it is clear 
from what is written above. But in the case of SWCNTs such limiting transition is productive only for Poisson's ratio. For nanotubes of small diameters the discussed generalized characteristics depend on diameter (size effect), and the mechanical properties are not defined by these two parameters. The geometric parameters (inclusive of chirality) are essential for full description. Later on we will show the effect of a difference of Young's moduli for SWCNTs at tension and compression.

The molecular dynamics calculations in this work are based on the Tersoff-Brenner-Stuart potential $[62,63]$. The subjects of simulations are the mechanical properties of SWCNTs under tension and compression. This standard method (including the effects for nonzero temperatures and the remarks on some restrictions for the description of the large deformations) is briefly written in the next section. In Part 2 the basic results obtained by numerical calculations are given. The kind of the nonlinear mechanical response to tension (or compression) of SWCNTs is established. The dependences of generalized Young's modulus and Poisson's ratio on magnitude and sign of strain are found. The influence of geometric parameters on mechanical characteristics is also analyzed. The boundaries of scale effect are estimated. The boundaries of instability and existence of various stable forms of nanotubes are established for axial compression.

\section{Modeling of atomic interactions in SWCNTs}

We use the standard molecular dynamics methods. The equations of motion are integrated in time for a system of carbon atoms with interatomic forces defined by the TersoffBrenner-Stuart interatomic potential (named also AIREBO potential) developed for a system of carbon and/or hydrogen atoms [62]. The considered potential consists of three parts:

$$
\mathrm{W}=\frac{1}{2} \sum_{\mathrm{i}} \sum_{\mathrm{j} \neq \mathrm{i}}\left[\mathrm{W}_{\mathrm{ij}}^{\mathrm{B}}+\mathrm{W}_{\mathrm{ij}}^{\mathrm{LJ}}+\sum_{\mathrm{k} \neq \mathrm{i}} \sum_{1 \neq \mathrm{i}, \mathrm{j}, \mathrm{k}} \mathrm{W}_{\mathrm{kij}}^{\mathrm{T}}\right] .
$$

The $\mathrm{W}_{\mathrm{ij}}{ }^{\mathrm{B}}$ term has the same functional form as the hydrocarbon REBO potential developed by Brenner [63] This term in the AIREBO potential gives the model of its reactive capabilities and describes only short-range interactions (distance between atoms $\mathrm{d}_{\mathrm{ij}}$ is less than cutoff radius $\mathrm{d}_{\text {cut }}=0.2 \mathrm{~nm}$ ). These interactions have strong coordination-dependence through a bond order parameter, which adjusts the attraction between the $i, j$ atoms based on the position of other nearby atoms and thus has 3-and 4-body dependence. The $\mathrm{W}_{\mathrm{ij}}^{\mathrm{LJ}}$ term adds long-range interactions $\left(0.2 \mathrm{~nm}<\mathrm{d}_{\mathrm{ij}}<1.02 \mathrm{~nm}\right)$ using a form similar to the standard Lennard-Jones potential. The $\mathrm{W}_{\text {kijl }}{ }^{\mathrm{T}}$ term is an explicit 4-body potential that describes various dihedral angle preferences in hydrocarbon configurations. It is known that such potential correctly reproduces energy of various structures of carbon and hydrocarbon compounds (in particular, suitable for simulation of carbon nanotubes). This potential is convenient for modeling the nanotube-polymer composite.

It is important to consider some restrictions of applicability of discussed model. For the Brenner potential (and related potentials) a nonphysical effect may appear at high deformations. For instance, the effect of overestimation of critical stresses at tension may be observed [64]. This effect is associated with a dramatic increase in the interatomic force near $\mathrm{d}_{\mathrm{ij}}=\mathrm{d}_{\text {cut }}$ (a so-called camelback on the force curve), which rises sharply with peak strain. This strange feature is a result of cutoff function action in the interatomic potential. The cutoff function $f\left(d_{i j}\right)$ is introduced in previously mentioned $\mathrm{W}_{\mathrm{ij}}{ }^{\mathrm{B}}$ term for taking into account only the nearest neighbors in covalent bonds. This function is constructed from three parts: $\mathrm{f}\left(\mathrm{d}_{\mathrm{ij}}\right)=1$ at $0<\mathrm{d}_{\mathrm{ij}}<0.17 \mathrm{~nm} ; \mathrm{f}\left(\mathrm{d}_{\mathrm{ij}}\right)=0.5+0.5 \cos \left(\mathrm{Ad}_{\mathrm{ij}}-\mathrm{B}\right)$ at $0.17 \mathrm{~nm}<\mathrm{d}_{\mathrm{ij}}<0.2 \mathrm{~nm}, \mathrm{f}\left(\mathrm{d}_{\mathrm{ij}}\right)=0$ at $\mathrm{d}_{\mathrm{ij}}>0.2 \mathrm{~nm}$ (constants A and $B$ ensure $f\left(d_{i j}\right)$ is continuously differentiable function). As a result the second derivative of the potential curve has a kink at $\mathrm{d}_{\mathrm{ij}}=0.17 \mathrm{~nm}$. There are complications for the description of situations when two originally close atoms were separated on distances over $0.17 \mathrm{~nm}$. This artificial feature gives the imaginary effect of strong hardening of nanotube before its rupture. One of possible ways for solving this problem is to increase the zone where cutoff function equals to unity $f\left(d_{i j}\right)=1$. But for this work the high strain of tubes was not considered. In our calculations it was found that the distance between closest neighboring atoms does not exceed $0.17 \mathrm{~nm}$ at $\varepsilon \leq 0.16$. In this work the strain $\varepsilon$ did not exceed 0.10 .

Calculations were carried out at various geometric parameters of SWCNTs $\left(6 \mathrm{~nm}<1_{0}<18.6 \mathrm{~nm}\right.$ and $0.4 \mathrm{~nm}<\mathrm{r}_{0}<4$ $\mathrm{nm})$ and temperatures $(\mathrm{T}=10 \mathrm{~K}, 300 \mathrm{~K}$ and $750 \mathrm{~K})$. The specific temperature was set by a Langevin thermostat [65]. Calculations at temperature $\mathrm{T}=10 \mathrm{~K}$ were carried out for the sake of methodological purposes.

Calculations of nanotubes mechanical properties are frequently performed without accounting for a temperature effect. In such simplified calculations one can avoid many difficulties (for instance thermal fluctuations), however, ignoring such factor is not always valid. Thus we have also performed verification of athermal methods by comparing the calculations at low temperatures with calculations at high temperatures. Later on it is shown that some characteristics can be defined only as the thermodynamic quantities (it results in some subtleties in calculation of their values). The number of atoms of SWCNTs in calculations varied from 360 up to 31680 . The time step during integration of atomic motion equations was $\Delta t=0.001$ ps. All of the calculations were carried out using the LAMMPS program [66].

During the molecular dynamics simulation, compression and tension were applied as follows: one atomic layer (the ring) at the edge section of SWCNT was "frozen", and one atomic layer at the opposite edge was given the constant speed $\mathrm{v}$ which provides either compression or tension of the nanotube. Calculations have been carried out to estimate the values of speed $\mathrm{v}$ corresponding to quasiequilibrium deformation. It was obtained that the calculated characteristics of SWCNTs do not depend on $\mathrm{v}$ for $\mathrm{v}<0.01$ $\mathrm{nm} / \mathrm{ps}$. In the subsequent calculations the magnitude of $\mathrm{v}$ was chosen equal to $0.001 \mathrm{~nm} / \mathrm{ps}$. The dependences of force $\mathrm{F}(\varepsilon)$ and Poisson's ratio $\mathrm{v}(\varepsilon)$ were computed using (1) and (3).

\section{References}

1. S. Iijima. Nature (London) 354, 56 (1991).

2. R. Tenne, L. Margulis, M. Genut, G. Hodcs. Nature 
(London) 360, 444 (1992).

3. M.M.J. Treacy, T.W. Ebbesen, J.M. Gibson. Nature (London) 381, 678 (1996).

4. E.W. Wong, P.E. Sheeehen, C.M. Lieber. Science 277, 1971 (1997).

5. N.G. Chopra, A. Zettl. Solid State Commun. 105, 297 (1998).

6. A. Krishnan, E. Dujardin, T.N. Ebbesen, P.N. Yianilos, M.M.J. Treacy. Phys. Rev. B58, 14013 (1998).

7. J. Muster, M. Burghard, S. Roth, C.S. Dusberg, E. Hernandez, A.J. Rubio. Vac. Sci. Technol. 16, 2796 (1998).

8. O. Lourie, H.D. Wagner. J. Mater. Sci. 13, 2418 (1998).

9. J.P. Salvetat, G.A.D. Briggs, J.M. Bonard, R.R. Baosa, A.J. Kulik, T. Stokli, N.A. Burnham, L. Forri. Phys. Rev. Lett. 82, 944 (1999).

10. J.P. Salvetat, J.M. Bonard, N.H. Thomson, A.J. Kulik, L. Ferro, W. Benoit, L. Zuppiroli. Appl. Phys. A69, 225 (1999).

11. J.P. Salvetat, A.J. Kulik, J.M. Bonard, G.A.D. Briggs, T. Stockli, K. Metenier, S. Bonnamy, F. Beguin, N.A. Burnham, L. Forro Adv. Mater. 11, 161 (1999).

12. Z.W. Pan, S.S. Xie, L. Lu, B.H. Chang, L.F. Sun, W.Y. Zhou, G. Wang, D.L. Zhang. Appl. Phys. Lett. 74, 3152 (1999).

13. P. Poncharal, Z.L. Wang, D. Ugarte, W.A. de Heer. Science. 283, 15 (1999).

14. D.A. Walters, L.M. Ericson, M.J. Casavant, J. Liu, D.T. Colbert, K.A. Smith, R.E. Smalley. Appl. Phys. Lett. 74, 3803 (1999).

15. Z.L. Wang, P. Poncharal, W.A. de Heer. J. Phys. Chem. Solids. 61, 1025 (2000).

16. M.F. Yu, O. Lourie, M.J. Dyer, K. Maloni, T.F. Kelly, R.S. Ruoff. Science. 287, 637 (2000).

17. M.F. Yu, B.S. Files, S. Arepally, R.S. Ruoff. Phys. Rev. Lett. 84, 5552 (2000).

18. M.F. Yu, B.I. Yakobson, R.S. Ruoff J. Phys. Chem. B104, 8764 (2000).

19. J.R. Wood, Q. Zhao, M.D. Frogley, E.R. Meurs, A.D. Prins, T. Peijs, D.J. Dunstan, H.D. Wagner. Phys. Rev. B62, 7571 (2000)

20. T.W. Tombler, C. Zhou, L. Alexseyev, J. Kong, H. Dai, L. Liu, C.S. Jayanthi, M. Tang, S.Y. Wu. Nature (London). 405, 769 (2000).

21. C.A. Cooper, R.J. Young. Proc. SPIE 4098, 172 (2000).

22. S. Xie, W. Li, Z. Pan, B. Chang, L. Sun. J. Phys. Chem. Solids. 61, 1153 (2000).

23. C.A. Cooper, R.J. Young, M. Halsall. Composites A32, 401 (2001).

24. Z.L. Wang, R.P. Gao, P. Poncharal, W.A. de Heer, Z.R. Dai, Z.W. Pan. Mater. Sci. Eng. C16, 3 (2001).

25. Z.L. Wang, R.P. Gao, Z.W. Pan, Z.R. Dai. Adv. Eng. Mater. 3, 657 (2001).

26. B.G. Demczyk, Y.M. Wang, J. Cumings, M. Hetman, W. Han, A. Zettl, R.O. Ritchie. Mater. Sci. Eng. A334, 173 (2002).

27. P.A. Williams, S.J. Papadikis, A.M. Patel, M.R. Falvo, S. Washbum, R. Superfine. Phys. Rev. Lett. 89, 255502 (2002).

28. P.A. Williams, S.J. Papadikis, A.M. Patel, M.R. Falvo, S. Washbum, R. Superfine. Appl. Phys. Lett. 82, 805 (2003).

29. S. Cuenot, C. Freitigny, S. Demoustier-Champagne, B.
Nysten. J. Appl. Phys. 93, 5650 (2003).

30. H.E. Troiani, M. Viki-Yoshida, G.A. Camacho-Bragado, M.A.L. Marques, A. Rubio, J.A. Ascencio, M. JoseYacaman. Nano Letters 3, 751 (2003).

31. P. Jaroenapibal, S.B. Chikkannanavar, D.E. Luzzi, S. Evoy. Appl. Phys. Lett. 85, 4328 (2004).

32. P. Jaroenapibal, D.E. Luzzi, S. Evoy, S. Arepalli. J. Appl. Phys. 98, 044301 (2005).

33. B. Lukic, J.W. Seo, E. Couteau, K. Lee, S. Gradecak, R. Berkecz, K. Htrnandi, S. Depleux, T. Cacciaguerra, F. Beguin, A. Fonseca, J.B. Nagi, G. Csanyi, A. Kis, A.J. Kulik, L. Forro. J. Appl. Phys. A80, 695 (2005).

34. J. Gaillard, M. Skove, A.M. Rao. Appl. Phys. Lett. 86, 233109 (2005).

35. A.R. Hall, L. An, J. Liu, L. Vicci, M.R. Falvo, R. Superfine, S. Washburn. Phys. Rev. Lett. 96, 256102 (2006).

36. M. Nakajiama, M. Arai, T. Fukuda. IEEE Trans. Nanotech. 5, 243 (2006).

37. K. Enomoto, S. Kitakata, T. Yasuhara, N. Ohtake, T. Kuzumaki, Y. Mitsuda. Appl. Phys. Lett. 88, 153115 (2006).

38. G. Guhados, W. Wan, X. Sun, J.L. Hutter. J. Appl. Phys. 101, 033514 (2007).

39. W. Ding, L. Calabri, K.M. Kohlhaas, X. Chen, D.A. Ditkin, R.S. Ruoff. Exper. Mech. 47, 25 (2007).

40. K.T. Kashyap, R.G. Patil. Bull. Mater. Sci. 31, 185 (2008).

41. X.L. Wei, Y. Liu, Q. Chen, M.S. Wang, L.M. Peng. Adv. Funct. Mater. 18, 1555 (2008).

42. B. Bhushan, X. Ling. Phys. Rev. B78, 045429 (2008).

43. A.K. Ojha, A. Materny. J. Raman Spectrosc. (2009).

44. B.I. Yakobson, P. Avouris. Topics Appl. Phys. 80, 287 (2001).

45. D. Qian, G.J. Wagner, W.K. Liu, M.F. Yu, R.S. Ruoff. Appl. Mech. Rev. 55, 495 (2002).

46. R.S. Ruoff, D. Qian, W.K. Liu. C. R. Physique 4, 993 (2003).

47. D. Srivastava, C. Wei, K. Cho. Appl. Mech. Rev. 56, 215 (2003).

48. M.F. Yu. Trans. ASME, J. Eng. Mater. and Techn. 126, 271 (2004).

49. J.P. Salvetat, S. Bhattacharyya, R.B. Pipes. Nanosci. J. Nanotechn. 6, 1857 (2006).

50. J.P. Salvetat, G. Desarmot, C. Gautier, P. Poulin. Lect. Notes Phys. 677, 439 Springer. Berlin, Heidelberg (2006).

51. A.V. Eletskii. Phys. Usp. 50, 225 (2007).

52. O.A. Shenderova, V.V. Zhirnov, D.W. Brenner. Crit. Rev. Solid State Mater. Sci. 27, 227 (2002).

53. L.M. Peng, Z.L. Zang, Z.Q. Xue, Q.D. Wu, Z.N. Gu, D.G. Pettifor. Phys. Rev. Lett. 85, 3249 (2000).

54. X. Zhao, Y. Liu, S. Inoue, T. Suzuki, R.O. Jones, Y. Ando. Phys. Rev. Lett. 92, 125502 (2004).

55. E. Hernandez, C. Goze, P. Bernier, A. Rubio. Phys. Rev. Lett. 80, 4502 (1998).

56. Z.T. Tu, Z.C. Ou-Yang. Phys. Rev. 65, 233407 (2002).

57. T. Vodenitcharova, L.C. Zhang. Phys. Rev. B68, 165401 (2003).

58. M.S. Dresselhaus, G. Dresselhaus, J.C. Charlier, E. Hernandez. Phil. Trans. R. Soc. Lond. A362, 2065 (2004).

59. Y. Huang, J. Wu, K.C. Hwang. Phys. Rev. B74, 245413 (2006). 
60. C.Y. Wang, L.C. Zhang. Nanotechnology 19, 075705 (2008).

61. J. Cai, C.Y. Wang, T. Yu, S. Yu. Phys. Scr. 79, 025702 (2009).

62. S.J. Stuart, A.B. Tutein, J.A. Harrison. J. Chem. Phys. 112, $6472(2000)$.
63. D.W. Brenner, O.A. Shenderova, J.A. Harrison, S.J. Stuart, B. Ni, S.B. Sinnott. J. Phys. C14, 783 (2002).

64. T. Belytschko, S.P. Xiao, G.C. Schatz, R.S. Ruoff. Phys. Rev. B65, 235430 (2002).

65. S.A. Adelman, J.D. Doll. J. Chem. Phys. 64, 2375 (1976). 66. S.J. Plimpton. J. Comp. Phys. 117, 1 (1995). 